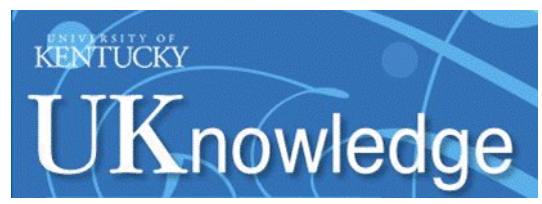

University of Kentucky

UKnowledge

$10-2015$

\title{
Titrating Clozapine amidst Recommendations Proposing High Myocarditis Risk and Rapid Titrations
}

Jose de Leon

University of Kentucky, jdeleon@uky.edu

\section{Y.-L. Tang}

Emory University

\section{T. Baptista}

Los Andes University, Venezuela

D. Cohen

Dutch Clozapine Collaboration Group, The Netherlands

P. F. J. Schulte

Dutch Clozapine Collaboration Group, The Netherlands

Follow this and additional works at: https://uknowledge.uky.edu/psychiatry_facpub

Part of the Psychiatry and Psychology Commons

Right click to open a feedback form in a new tab to let us know how this document benefits you.

\section{Repository Citation}

de Leon, Jose; Tang, Y.-L.; Baptista, T.; Cohen, D.; and Schulte, P. F. J., "Titrating Clozapine amidst Recommendations Proposing High Myocarditis Risk and Rapid Titrations" (2015). Psychiatry Faculty Publications. 35.

https://uknowledge.uky.edu/psychiatry_facpub/35

This Commentary is brought to you for free and open access by the Psychiatry at UKnowledge. It has been accepted for inclusion in Psychiatry Faculty Publications by an authorized administrator of UKnowledge. For more information, please contact UKnowledge@lsv.uky.edu. 


\section{Titrating Clozapine amidst Recommendations Proposing High Myocarditis Risk and Rapid Titrations}

Digital Object Identifier (DOI)

http://dx.doi.org/10.1111/acps.12421

Notes/Citation Information

Published in Acta Psychiatrica Scandinavica, v. 132, issue 4, p. 242-243.

(C) 2015 John Wiley \& Sons A/S.

This is the peer reviewed version of the following article: de Leon, J., Tang, Y.-L., Baptista, T., Cohen, D. and Schulte, P. F. J. (2015), Titrating clozapine amidst recommendations proposing high myocarditis risk and rapid titrations. Acta Psychiatrica Scandinavica, which has been published in final form at http://dx.doi.org/10.1111/acps.12421. This article may be used for non-commercial purposes in accordance with Wiley Terms and Conditions for Self-Archiving.

This commentary is available at UKnowledge: https://uknowledge.uky.edu/psychiatry_facpub/35 
Titrating Clozapine amidst Recommendations Proposing High Myocarditis Risk and Rapid Titrations J. de Leon, Y.-L. Tang, T. Baptista, D. Cohen, and P. F. J. Schulte This is the peer reviewed version of the following article: de Leon, J., Tang, Y.L., Baptista, T., Cohen, D. and Schulte, P. F. J. (2015), Titrating clozapine amidst recommendations proposing high myocarditis risk and rapid titrations. Acta Psychiatrica Scandinavica, which has been published in final form at http://dx.doi.org/10.1111/acps.12421. This article may be used for noncommercial purposes in accordance with Wiley Terms and Conditions for SelfArchiving. 


\section{Acta Psychiatrica Scandinavica}

Text: 1300 words

References: 5

Titrating clozapine amidst recommendations proposing high myocarditis risk and rapid titrations

J. de Leon, ${ }^{\text {a,b* }}{ }^{\text {Y }}$-LTang, ${ }^{c, d}$ T. Baptista, ${ }^{e}$ D. Cohen, ${ }^{\text {f.g }}$ P.F.J. Schulte ${ }^{\text {f.h }}$

${ }^{a}$ University of Kentucky Mental Health Research Center at Eastern State Hospital, Lexington, KY, USA.

${ }^{b}$ Psychiatry and Neurosciences Research Group (CTS-549), Institute of Neurosciences, University of

Granada, Granada, Spain, and Biomedical Research Centre in Mental Health Net (CIBERSAM), Santiago Apóstol Hospital, University of the Basque Country, Vitoria, Spain.

${ }^{c}$ Department of Psychiatry and Behavioral Sciences, Emory University School of Medicine, Atlanta, GA 30322, USA.

${ }^{\mathrm{d} B e i j i n g ~ K e y ~ L a b o r a t o r y ~ o f ~ M e n t a l ~ D i s o r d e r s, ~ D e p a r t m e n t ~ o f ~ P s y c h i a t r y, ~ B e i j i n g ~ A n d i n g ~ H o s p i t a l, ~}$ Capital Medical University, Beijing 100088, China.

eDepartment of Physiology, Los Andes University Medical School, Mérida, Venezuela.

fDutch Clozapine Collaboration Group, Castricum, The Netherlands.

${ }^{\mathrm{g}}$ FACT-team in Heerhugowaard, Department of Severe Mental Illness, Mental Health Services NorthHolland North, The Netherlands.

${ }^{\text {h}}$ Specialized Treatment Division, Mental Health Services North-Holland North, Alkmaar, The Netherlands.

Running title: Clozapine titration

*Corresponding author: Jose de Leon, M.D., UK Mental Health Research Center at Eastern State Hospital, 1350 Bull Lea Rd., Lexington, KY 40511. Phone (859) 246-8440. Fax (859) 246-8446 e-mail: jdeleon@uky.edu 
Key words: clozapine; clozapine/administration and dosage; drug-related side effects and adverse reactions; mortality; myocarditis. 
Ronaldson and Fitzgerald (1) propose that many cases of clozapine-induced myocarditis are overlooked and the actual worldwide incidence in clozapine patients is around 3\%, which is in conflict with published evidence. This extraordinarily high estimation was calculated by averaging rates of $1.1 \%$ and 5.0\% from two Australian studies with 122 and 124 clozapine patients, respectively. After reviewing the literature in English, Cohen et al. (2) estimated the incidence of clozapine-induced myocarditis to be $0.07-0.6$ per 1000 in non-Australian countries. In China, clozapine is widely prescribed. Until very recently, clozapine was a first-line antipsychotic prescribed in $25-60 \%$ of schizophrenia patients and in many patients with severe mood disorders (3). A 2015 search of the literature in Chinese reveals that clozapine-induced myocarditis has been extremely rarely reported.

If the $3 \%$ incidence is correct, pharmacoepidemiological studies should demonstrate that thousands of non-Australian clozapine patients are dying every year but they suggest the opposite; clozapine may prevent cardiovascular deaths compared to other antipsychotics. In an 11-year follow-up mortality study in 66,000 Finnish schizophrenia patients, clozapine showed the lowest mortality with an adjusted hazard ratio (HR) of 0.74 (95\% confidence interval, CI 0.60-0.91). In a 5-year follow-up of almost 7,000 Finnish patients with first-onset schizophrenia, clozapine showed an adjusted odds ratio (OR) for cardiovascular death of 0.23 (CI, 0.05-1.02). In a schizophrenia cohort study of 26,000 Swedish patients, clozapine showed an adjusted OR for all deaths of 0.92 (CI 0.70-1.22). In a 3-year study of a cohort of 67,000 patients from the US Clozapine National Registry, there was no death attributed to myocarditis and less than 10 deaths attributed to two cardiac categories: 1) acute myocardial infarction and 2) conduction disorders or sudden death. In a 6-10 year follow-up of a cohort of 1000 clozapine patients in Maryland (USA), cardiac deaths were 35\% (32/92) of clozapine deaths and the adjusted standardized mortality rates for cardiovascular mortality were comparable to risperidone deaths. In a 5year follow-up of a cohort from London (UK) including 14,000 patients with serious mental illness, clozapine was associated with lower mortality (adjusted HR=0.4; CI 0.2-0.7). 
We believe that it is not correct to extrapolate these unusual incidences from two Australian studies totaling less than 300 patients titrated on clozapine to the thousands of patients titrated worldwide. Rapid clozapine dose titration has been suggested as an explanation for the risk of myocarditis by a 2012 Australian article titled "Rapid clozapine dose titration and concomitant sodium valproate increase the risk of myocarditis with clozapine: a case-control study". Rapid titration may be one of the key factors contributing to the very high rates of clozapine-induced myocarditis in Australia. This is supported by an ongoing Venezuelan prospective clozapine study, by one of us, following 59 patients longitudinally. Most of them were started at low doses (<100 mg/day) and given slow titrations. The only subject with suspected myocarditis (reported chest discomfort, positive troponine I and ST segment abnormalities at day 7 of clozapine administration) was a 30-year-old male started on clozapine at the high dose of 200 $\mathrm{mg} / \mathrm{day}$.

We suggest that instead of raising unfounded clinical concerns for non-Australians, Australian prescribers should consider adopting slower titrating schedules, as a prior lamotrigine pharmacology story tells us. Lamotrigine-induced Stevens-Johnson is another idiosyncratic adverse drug reaction (ADR) associated with rapid titrations. It was radically reduced when the manufacturers recommended a slow titration in their prescribing information (or package insert), specifying the need of an even lower initial dose and slower titration in patients taking valproate, an inhibitor of lamotrigine's metabolism. Slow clozapine titration strategies, including a slower pace for patients taking clozapine inhibitors, should be studied as a strategy for preventing myocarditis in Australia.

At the other extreme from Ronaldson et al. (1), Ifteni et al. (4) extrapolated from a small sample, recommending rapid titration as safe. They studied 38 Romanian clozapine-naïve patients with schizophrenia who were prescribed an average clozapine dose of $156 \mathrm{mg} /$ day on the first day, with a range of 25 to $400 \mathrm{mg} /$ day, and an average maximum dose of $409 \mathrm{mg} /$ day on average at day 7 . We recommend against this type of rapid titration in clozapine-naïve patients unless they are very closely monitored in research settings. 
To an inexperienced clinician already concerned about clozapine ADR risk and the practical difficulties of starting new patients on clozapine, it would seem quite confusing and possible intimidating after reading these articles written by us, the so-called clozapine experts. Is further confusing or intimidating clinicians concerning clozapine utilization a problem? Yes, it is a major problem. Metaanalyses unquestionably demonstrate that clozapine is the most effective of all antipsychotics, but authors from many countries, except China, argue that clozapine is severely underutilized in spite of its documented efficacy for treatment-refractory schizophrenia or schizophrenia-associated suicidality. Elaborating on the benefits of clozapine's off-label uses would require a longer article.

Regarding Ifteni et al.'s proposal of rapid titration in clozapine-naïve patients (4), we recommend very slow clozapine titration with careful monitoring in a Dutch guideline mainly developed for outpatients (http://www.clozapinepluswerkgroep.nl/wp-content/uploads/2013/07/Guideline-for-the-useof-Clozapine-2013.pdf, accessed on 25 February 2015) and in a pharmacokinetic guideline for inpatients (5). The Dutch guideline recommends initial doses of 6.25 or $12.5 \mathrm{mg}$, doubling the dose the second day, and then $25-50 \mathrm{mg} /$ day increases, but no more than $300 \mathrm{mg} /$ day for the first 14 days. The pharmacokinetic guideline recommends starting with $25 \mathrm{mg}$ (12.5 mg in patients expected to have slower clozapine metabolism), increasing by 25 (12.5) $\mathrm{mg} /$ day in the first week, and then by 50 (25) $\mathrm{mg} /$ day reaching 100 (50) $\mathrm{mg} /$ day at the end of the first week, 200 (100) mg/day at the end of the second week, and 300 (150) $\mathrm{mg} / \mathrm{day}$ at the end of the third week. Both guidelines insist on slower titrations after abnormalities in orthostatic changes of blood pressure and pulse, or sedation and initial doses at night.

Our conclusion, for those who revere the "science" of evidence-based medicine, is that if it is correct that in non-Australian countries clozapine-induced myocarditis has an incidence $<1 \%$, then an evidence-based approach will not work with this rare frequency because gathering the evidence would require support from the deep pockets of pharmaceutical companies that can afford to fund studies of thousands of patients. No pharmaceutical company is going to support intensive studies to establish or rule out clozapine-induced myocarditis as an idiosyncratic ADR probably associated with rapid titration. 
Our take-home message for clinicians includes the hope that they will forgive us, the clozapine experts, for our inconsistent messages on the speed with which clozapine can safely be titrated. For our part, we think that we should refrain from making any more comments based on extrapolations from small to very small studies. Although there are more than 10,000 clozapine articles in PubMed, but this is not enough for definitive evidence-based recommendations for clozapine titration on a worldwide basis. In the midst of this large number of articles, some data ignored by non-Chinese clozapine researchers supports the hypothesis that clozapine metabolism and dosing may be different in those with Chinese ancestry, which is presumably explained by a pharmacogenetic difference (5). If confirmed true that the Chinese do indeed need lower clozapine doses and, presumably, slower titration, this may also be relevant in preventing clozapine-induced myocarditis in Chinese people, possibly in other East Asians, and Caucasians who are CYP2C19 poor metabolizers (5). If this pharmacogenetic- and ethnic-based dosing difference has not been definitively established, imagine how limited the clozapine evidence-based literature is. Unfortunately, as Naylor declared, "Clinical medicine seems to consist of a few things we know, a few things we think we know (but probably don't), and lots of things we don't know at all.” In the context of limited evidence, we should err on the side of recommending safety without inducing more clozapine phobia and encourage a trial of clozapine with slow titration in all patients with treatmentresistant schizophrenia. 
Acknowledgements: This article was completed without any external funding. Lorraine Maw, M.A., at the UK Mental Health Research Center helped with editing.

Declaration of Interest: No commercial organizations had any role in the completion or publication of this article. Drs. de Leon, Baptista, Cohen and Schulte declare no competing interest during the last 36 months. Dr Tang has received a pilot research grant from Janssen Pharmaceuticals, Inc, from 2004-2015.

\section{References}

1. RONALDSON K, FITZGERALD P. Clozapine-induced myocarditis, a widely overlooked adverse reaction. Acta Psychiatr Scand 2015 (in press).

2. Cohen D, Bogers JP, van Dijk D, BAKKer B, Schulte PF. Beyond white blood cell monitoring: screening in the initial phase of clozapine therapy. J Clin Psychiatry 2012;73:1307-1312.

3. TANG YL, MaO PX, Jiang F, Chen Q, WAng CY, Cai ZJ, Mitchell PB. Clozapine in China. Pharmacopsychiatry 2008;41:1-9.

4. Ifteni P, Nielsen J, Burtea V, Correll CU, Kane JM, Manu P. Effectiveness and safety of rapid clozapine titration in schizophrenia. Acta Psychiatr Scand 2014;130:25-9.

5. SPINA E, DE LEON J. Clinical applications of CYP genotyping in psychiatry. J Neural Transm $2015 ; 122: 5-28$. 